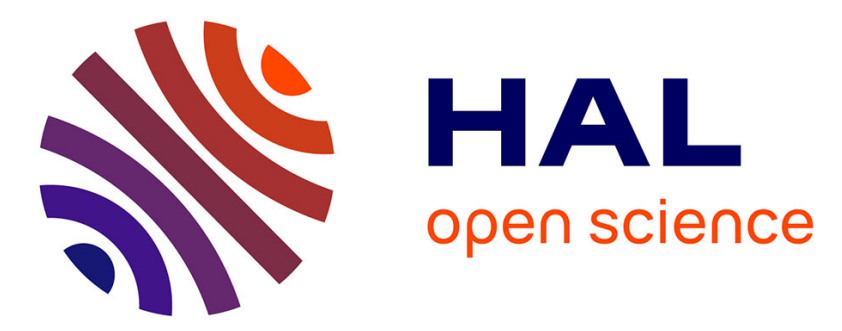

\title{
The Influence of Specimen Thickness on the High Temperature Corrosion Behavior of CMSX-4 during Thermal-Cycling Exposure
}

Robert Orosz, Ulrich Krupp, Hans-Jürgen Christ, Daniel Monceau

\section{- To cite this version:}

Robert Orosz, Ulrich Krupp, Hans-Jürgen Christ, Daniel Monceau. The Influence of Specimen Thickness on the High Temperature Corrosion Behavior of CMSX-4 during Thermal-Cycling Exposure. Oxidation of Metals, 2007, vol. 68, pp.165-176. 10.1007/s11085-007-9067-9 . hal-00806045

\section{HAL Id: hal-00806045 https://hal.science/hal-00806045}

Submitted on 29 Mar 2013

HAL is a multi-disciplinary open access archive for the deposit and dissemination of scientific research documents, whether they are published or not. The documents may come from teaching and research institutions in France or abroad, or from public or private research centers.
L'archive ouverte pluridisciplinaire HAL, est destinée au dépôt et à la diffusion de documents scientifiques de niveau recherche, publiés ou non, émanant des établissements d'enseignement et de recherche français ou étrangers, des laboratoires publics ou privés. 


\title{
The Influence of Specimen Thickness on the High Temperature Corrosion Behavior of CMSX-4 during Thermal-Cycling Exposure
}

\author{
R. Orosz $\cdot$ U. Krupp $\cdot$ H.-J. Christ $\cdot$ D. Monceau
}

\begin{abstract}
CMSX-4 is a single-crystalline Ni-base superalloy designed to be used at very high temperatures and high mechanical loadings. Its excellent corrosion resistance is due to external alumina-scale formation, which however can become less protective under thermal-cycling conditions. The metallic substrate in combination with its superficial oxide scale has to be considered as a composite suffering high stresses. Factors like different coefficients of thermal expansion between oxide and substrate during temperature changes or growing stresses affect the integrity of the oxide scale. This must also be strongly influenced by the thickness of the oxide scale and the substrate as well as the ability to relief such stresses, e.g., by creep deformation. In order to quantify these effects, thin-walled specimens of different thickness $(t=100-500 \mu \mathrm{m})$ were prepared. Discontinuous measurements of their mass changes were carried out under thermal-cycling conditions at a hot dwell temperature of $1100{ }^{\circ} \mathrm{C}$ up to 300 thermal cycles. Thin-walled specimens revealed a much lower oxide-spallation rate compared to thick-walled specimens, while thinwalled specimens might show a premature depletion of scale-forming elements. In order to determine which of these competetive factor is more detrimental in terms of a component's lifetime, the degradation by internal precipitation was studied using
\end{abstract}

R. Orosz

Betriebsforschungsinsititut VDEh, 40237 Dusseldorf, Germany

U. Krupp $(\bowtie)$

Faculty of Engineering and Computer Science, University of Applied Sciences, Osnabrück, 49009 Osnabruck, Germany

e-mail: u.krupp@fh-osnabrueck.de

H.-J.Christ

Institut für Werkstofftechnik, Universität Siegen, 57068 Siegen, Germany

D. Monceau

CIRIMAT, ENSIACET-INPT, Toulouse Cedex 4 31077, France 
scanning electron microscopy (SEM) in combination with energy-dispersive X-ray spectroscopy (EDS). Additionally, a recently developed statistical spallation model was applied to experimental data [D. Poquillon and D. Monceau, Oxidation of Metals, 59, 409-431 (2003)]. The model describes the overall mass change by oxide scale spallation during thermal cycling exposure and is a useful simulation tool for oxide scale spallation processes accounting for variations in the specimen geometry. The evolution of the net-mass change vs. the number of thermal cycles seems to be strongly dependent on the sample thickness.

Keywords Thermal-cycling exposure - Alumina-forming alloy CMSX-4 . Thin-walled specimens · Oxide spallation model

\section{Introduction}

The resistance to enhanced internal corrosion attack of high temperature alloys is due to their ability to form and maintain a protective oxide scale. In order to exhibit best protective properties, the scale should be slow-growing, very stable, continuous, and adherent [2]. Commercial alloys designed for high-temperature applications rely upon the formation of either chromia $\left(\mathrm{Cr}_{2} \mathrm{O}_{3}\right)$ or alumina $\left(\mathrm{Al}_{2} \mathrm{O}_{3}\right)$ scales. The latter one is formed on CMSX-4, a single-crystalline nickel-base superalloy used for gas turbine blades due to its excellent mechanical properties combined with high-temperature oxidation resistance. In service, particular in the case of aero engines, the blades are exposed to thermal-cycling conditions. These conditions lead to an increase in the susceptibility to oxide-scale failure on CMSX4 , and may reduce service life significantly [3,4]. The repeated descaling of the external oxide layer is accompanied by scale-rehealing processes afterwards, and thus, by depletion of the scale forming element, cf. [5-7]. As a consequence of this, formation of less-protective oxide scales, transition to internal oxidation and nitridation may occur in combination with the dissolution of the strengthening $\gamma^{\prime}$ phase, leading to a significant degradation of the performance of nickel-base superalloys [6-8], the knowledge of which is of particular importance of thin-walled sections of precision-cast gas-turbine blades.

In this context, oxidation-limited life of components until onset of "breakaway oxidation" can be predicted quite easily by using a model, which requires only the input of some measured data [9]: The scale growth rate, the critical element content for scale rehealing and some modification factors to account for differences in surface to volume ratios of components and/or specimens of different shapes. Obviously, the geometry of specimens has an important effect on the oxide scale adherence. Although thick components are evaluated as to be more prone to oxide spallation, investigations on several thin-walled FeCrAl-base alloys revealed, that scale adherence is strongly affected by the mechanical properties of the alloy as well as by the type and amount of reactive-element addition [9]. Pint et al. [10] have considered a wide range of experimental data obtained on alumina-forming alloys, among those also Ni-base alloys, in order to illustrate the effect of thermal-cycling frequency and test procedures. 
The objective of the present study was to investigate the effect of the specimen's thickness on the oxide scale spallation behavior during thermal-cycling exposure. It is expected, that the mechanical strength, which depends on the specimen's thickness, has a great influence on the relief of stresses, which arise during cyclic oxidation within the substrate/scale-system. The application of a probabilistic spallation model [1] has been applied to quantify this effect. This model allows to fit the kinetics of cyclic oxidation (net mass gain as a function of number of cycles) using only two parameters: the parabolic rate constant " $k_{\mathrm{p}}$ " which describes the isothermal oxidation kinetics during the high temperature dwells, and a parameter " $p$ " which represents the proportion of the oxide scale which spalls at each cycle (usually during cooling). When the cyclic oxidation kinetics can be fitted with such a model, it is possible to calculate in return the amount of metal consumed and to extrapolate the results to longer times, i.e., to quantify cyclic-oxidation tests $[1,11-$ 13]. In the present study, the application of a cyclic-oxidation-kinetics model allows also to better understand the effect of the sample thickness, in particular to determine if the sample thickness has an effect on the amount of spalling alone (" $p$ ") or an effect on both spalling and the isothermal oxidation kinetics (" $k_{\mathrm{p}}$ ").

\section{Experimental Details}

Specimens of different thicknesses $(t=100-500 \mu \mathrm{m})$ were cut from a rod of $9 \mathrm{~mm}$ diameter using a slow-speed, diamond-cutting wheel. The rod had been spark eroded out of a gas-turbine blade made of CMSX-4. The chemical composition is given in Table 1.

The surfaces were wet-ground to a 2500 -grit finish using SiC paper. Afterwards, the samples were polished with $6 \mu \mathrm{m}$ and $1 \mu \mathrm{m}$ diamond suspension to a mirror-like finish. Prior to the corrosion tests, the specimens were cleaned ultrasonically in ethanol. The experimental setup, which is shown schematically in Fig. 1, consists of a computer-controlled actuator, which can move a furnace periodically up and down for any given heating and cooling period. A part of a vertically fixed quartz-glass tube is inserted in the furnace. All specimens were inserted into alumina crucibles, which were held in a defined (lower) position of the quartz glass tube. In this position the specimens were exposed to laboratory air at $1100{ }^{\circ} \mathrm{C}$ for $1 \mathrm{~h}$ dwellperiods followed by $25 \mathrm{~min}$. cooling periods at a temperature of about $50{ }^{\circ} \mathrm{C}$, while the furnace remained at the upper position.

After a certain number of thermal cycles, the crucible was removed from the quartz glass tube and each of the specimens was weighed using a Sartorius CP $124 \mathrm{~S}$ micro balance having a resolution of $100 \mu \mathrm{g}$. Subsequently, the specimens were

Table 1 Chemical composition of the single-crystalline Ni-base superalloy CMSX-4

\begin{tabular}{|c|c|c|c|c|c|c|c|c|c|c|c|}
\hline & $\mathrm{Ni}$ & $\mathrm{Cr}$ & $\mathrm{Al}$ & $\mathrm{Ti}$ & Co & $\mathrm{Ta}$ & Mo & W & $\operatorname{Re}$ & $\mathrm{Hf}$ & S \\
\hline $\mathrm{wt} \%$ & Bal. & 6.0 & 5.6 & 1.0 & 10.0 & 6.0 & 0.6 & 6.0 & 3.0 & 0.1 & $<12 \mathrm{ppm}$ \\
\hline at $\%$ & Bal. & 7.0 & 12.6 & 1.3 & 10.3 & 2.0 & 0.4 & 2.0 & 1.0 & 0.03 & $<23 \mathrm{ppm}$ \\
\hline
\end{tabular}


Fig. 1 Schematic

representation of the

experimental setup showing the furnace in upper position (lower position is shown by the dashed rectangle)

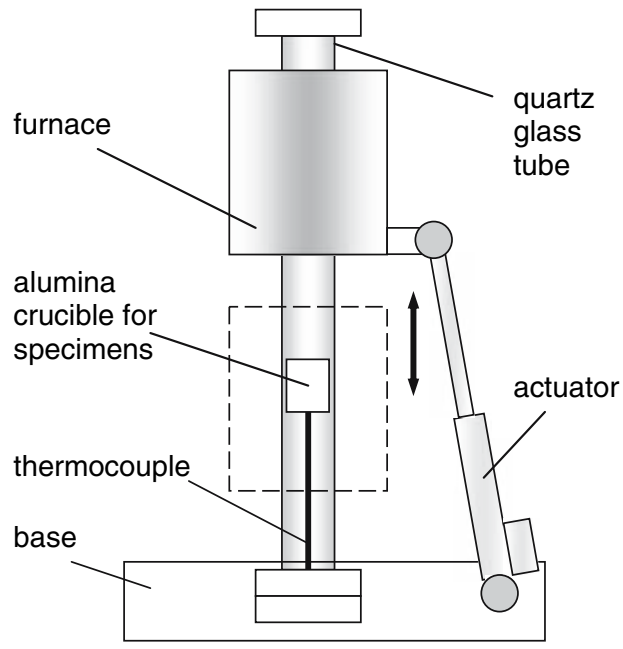

placed back into the crucible and inserted again into the initial position, being held in place throughout the testing by a FeCrAl-wire. A Ni-NiCr-thermocouple was used for controlling the actual temperature and for recording the heating and cooling curve. It takes $7 \mathrm{~min}$ for the specimen to reach the hot dwell temperature at $T=1100{ }^{\circ} \mathrm{C}$ in the furnace, and $15 \mathrm{~min}$ to cool the specimen to $T=50{ }^{\circ} \mathrm{C}$. The $15 \mathrm{~min}$ and $7 \mathrm{~min}$ duration were added to the total duration of cold and hot dwell periods, respectively.

\section{Experimental Results}

Thermal-cycling exposure of all specimens revealed weight loss under the given conditions $\left(1 \mathrm{~h}\right.$ hot dwell time at $1100{ }^{\circ} \mathrm{C}, 1 / 4 \mathrm{~h}$ cold dwell time at $50{ }^{\circ} \mathrm{C}$ ), at the latest after 42 thermal cycles. Figure 2 shows the net mass change of the specimens (100-500 $\mu \mathrm{m}$ thickness) after 42, 75, 102, 196 and 300 thermal cycles. The relative error due to the balance accuracy and due to the error on the surface area determination leads to deviation of the measured values that lies in between $\pm 5 \%$.

The specimen thickness has strong impact on the net mass change. When plotting the net mass change after 300 thermal cycles in dependence on the specimen thickness $t$ (Fig. 3), an almost linear relationship between specimen thickness and the net mass gain after 300 thermal cycles becomes evident. The macroscopic photographs document the increased susceptibility to scale spallation. The bright areas correspond to bare metal surface (Fig. 4).

The macroscopic photographs shown in Fig. 4 reveal an enhanced spallation susceptibility with increasing specimen thickness. It is obvious that the effect of thickness is not due to the fact that spalling is restricted to the edges or side faces of the samples. An image analysis tool $\left(\operatorname{Image}^{\mathrm{R}}{ }^{\mathrm{B}}\right.$ ) has been used in order to account for the spalled area from each of these specimens shown in Fig. 4. The percentage of descaled surface area is shown in Fig. 5 as a function of the specimen thickness. 


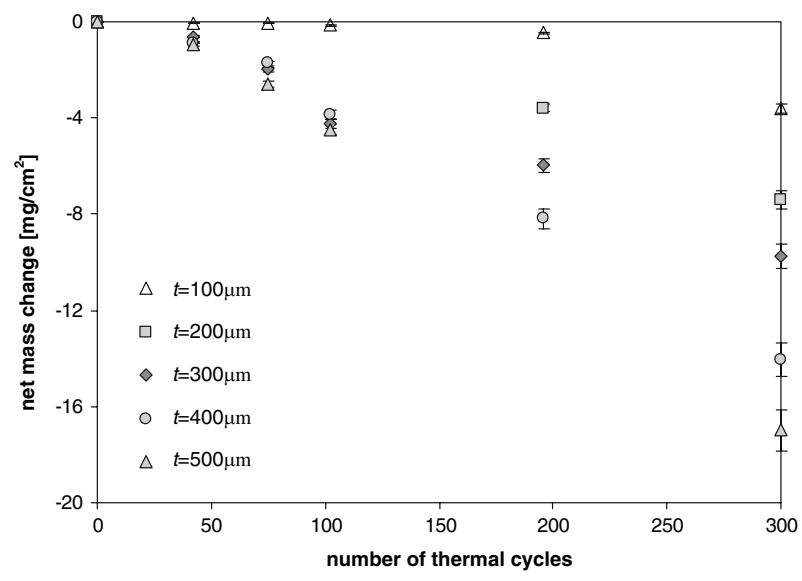

Fig. 2 Net mass change versus exposure time for different specimen thicknesses. Thermal-cycling exposure at $T=1100{ }^{\circ} \mathrm{C} 1 \mathrm{~h}$ hot dwell times at $T=1100{ }^{\circ} \mathrm{C}$ and $0.25 \mathrm{~h}$ cooling-down periods to $T=50^{\circ} \mathrm{C}$

Fig. 3 Net mass change after 300 thermal cycles in dependence on the specimen thickness

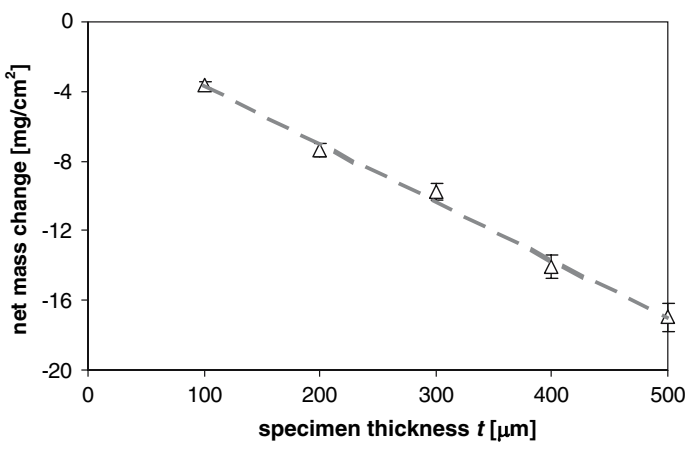

Obviously, the oxide/substrate composite suffers high cooling stresses, which become high enough to cause scale spallation. Because of the higher mechanical load that can be accommodated by thicker specimens, stress relief by substrate creep should become much more difficult or impossible for specimens with thickness ranging somewhere between $t=300 \mu \mathrm{m}$ and $400 \mu \mathrm{m}$ under the studied conditions. The values for the descaled areas abruptly increase by a factor of ten.

An EDS-element analysis was used to characterize the oxide formed on CMSX4. The example in Fig. 6 shows a part of an oxide scale (after 196 thermal cycles; $500 \mu \mathrm{m}$ thick specimen) and the typical composition of the oxide scale formed during the initial stages.

SEM investigations revealed that the scale structure shown in Fig. 6 cannot be considered to be representative for every location on the specimen after 196 cycles. Usually, the less stable compounds $(\mathrm{NiO}, \mathrm{CoO})$ as well as the fast-growing $\mathrm{TiO}_{2}$ were not present anymore after high numbers of thermal cycles due to spalling. Additionally, in order to quantify the material's degradation process during thermal- 


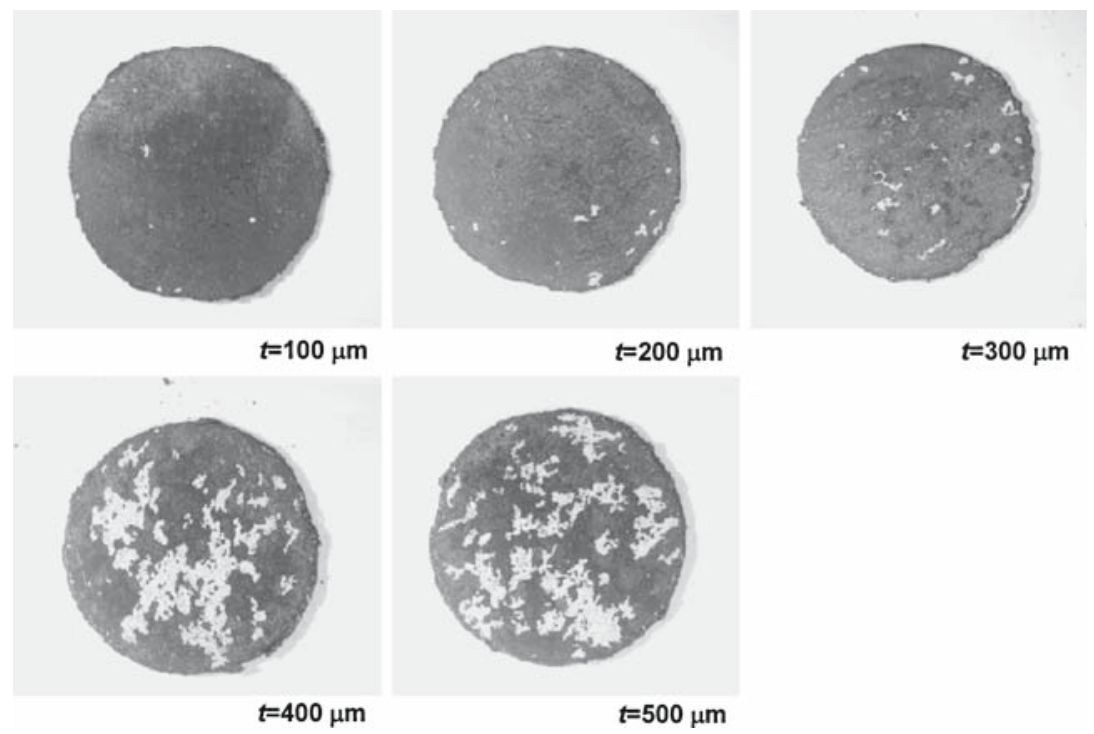

Fig. 4 Macroscopic photographs of the specimens' surfaces after 300 thermal cycles

Fig. 5 Percentage of descaled surface area in dependence of the specimen thickness $t$

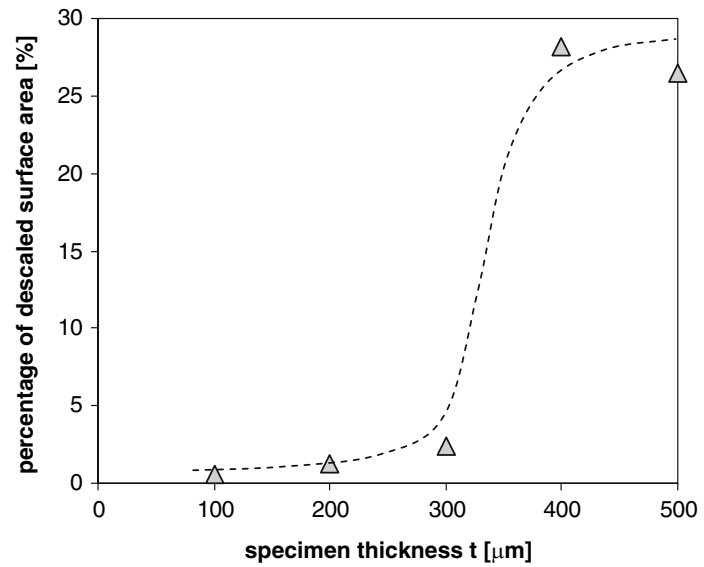

specimen thickness $\mathbf{t}[\mu \mathrm{m}]$

cycling exposure, the subsurface area was investigated by SEM in combination with EDS analysis. The cross sections represented in Fig. 7 provides a typical picture of the corrosion-affected zones in the near-surface area.

Considering the near-surface areas of the alloy, it is interesting to note that the extent of external and internal corrosion is quite comparable for each specimen. That means that the corrosion mechanism seems to be quite independent of the specimen thickness, except for the thinnest one. This specimen shows first indication of "breakaway oxidation", massive internal nitridation (TiN, AlN), as well as internal oxidation $\left(\mathrm{Al}_{2} \mathrm{O}_{3}\right)$. EDS analysis revealed, that high contents of Ta 


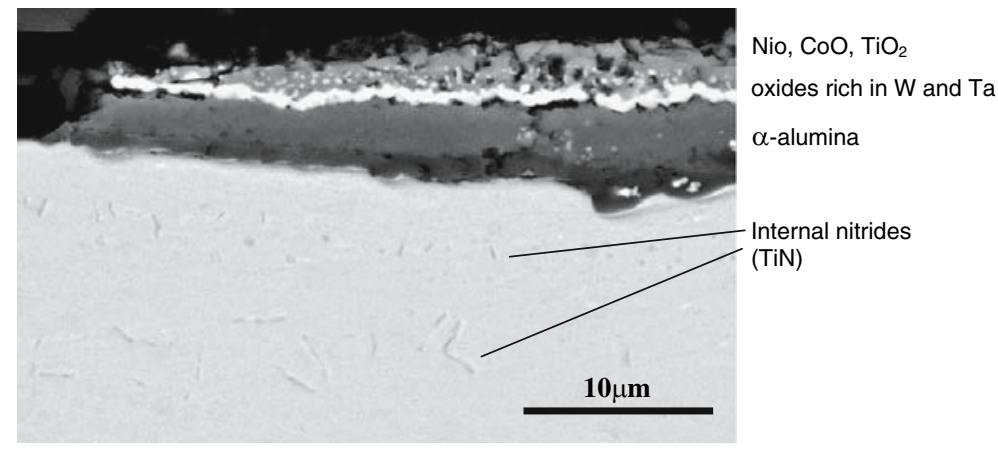

Fig. 6 Scale formation on a $500 \mu \mathrm{m}$ thick specimen after 196 thermal cycles at $1100{ }^{\circ} \mathrm{C}$ with a descaled area on the left-hand side

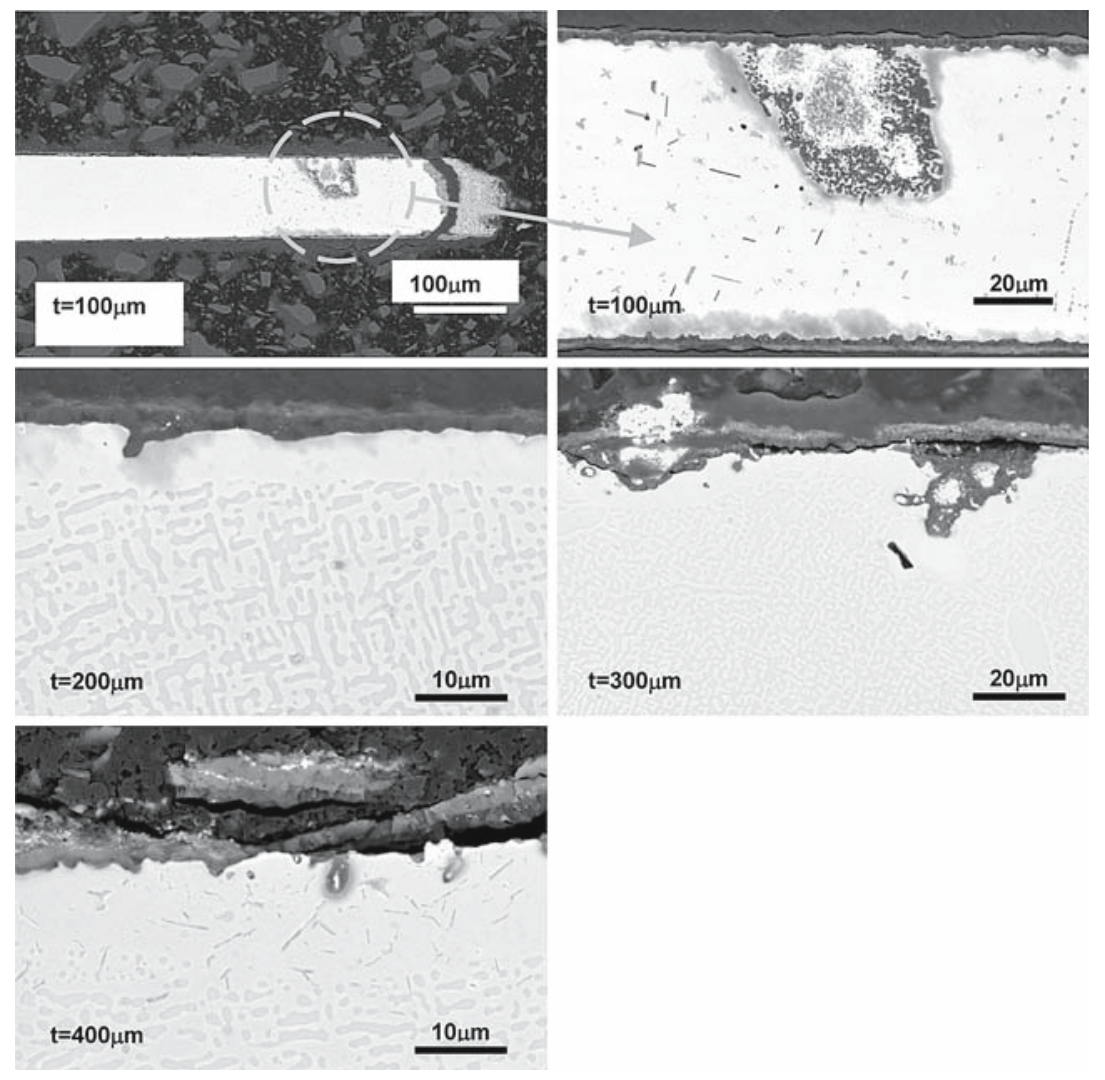

Fig. 7 Typical appearances of the corrosion affected zones in dependence on the specimen thickness after 300 thermal cycles 
may contribute to this enhanced corrosion process. In general, the intensity of the corrosion attack is not homogenous, but locally heterogeneous. In order to assess to the extent to which the corrosion process has already proceeded, an analysis of the depletion depth of the $\gamma^{\prime}$-phase was performed. This quantity can be utilized as a rough indicator for the local $\mathrm{Al}$ content of the alloy and represents an important hint, whether self-rehealing of the alumina scale can be expected or not. $\gamma^{\prime}$-depletion measurements have been carried out on each of the specimens after 196 and 300 thermal cycles. Figure 8 represents the average values for each of the specimens. For this purpose, the $\gamma^{\prime}$-depletion depths was determined in 25-30 individual measurements at different specimen locations.

The $\gamma^{\prime}$-depletion depth of $10 \mu \mathrm{m}$ is much lower than $100 \mu \mathrm{m}$, so it can be assumed that there is no effect of sample thickness on $\mathrm{Al}$ depletion, except that a higher spallation probability for thicker samples might result in higher $\mathrm{Al}$ consumption. One can assume that the $\mathrm{Al}$ content is approximately of a constant value at the interface between the $\gamma / \gamma^{\prime}$ substrate and the $\gamma^{\prime}$ depleted surface layer. The measurements revealed that the thickness of the $\gamma^{\prime}$-depleted surface layer varies between $8-12 \mu \mathrm{m}$. As long as this thickness is distant from the center of the alloy appreciable dependence on the specimen thicknesses should be expected.

\section{Modeling of Cyclic Oxidation Kinetics}

It has been shown in the experimental part that the cyclic oxidation kinetics strongly depend on the sample thickness (Fig. 2). Cyclic oxidation kinetics, in terms of netmass change as a function of the number of cycles, result from the combination of net-mass gain due to oxygen (or other oxidant) uptake and net-mass loss due to partial or full oxide spallation. In the present case, it was shown that the mass gain is due to the formation of an external oxide layer, which is formed of transient oxides $(\mathrm{NiO}, \mathrm{CoO}, \mathrm{TiO} 2)$ and of a continuous layer of $\alpha$ alumina in contact with the

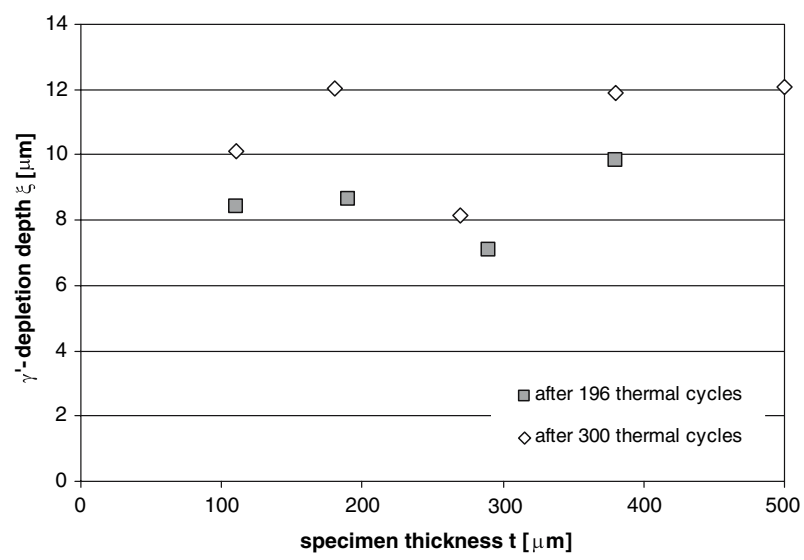

Fig. 8 Measured $\gamma^{\prime}$-depletion depths after 196 and after 300 thermal cycles $(1 \mathrm{~h}$ hot dwell time at $1100{ }^{\circ} \mathrm{C}, 1 / 4 \mathrm{~h}$ cold dwell time at $50{ }^{\circ} \mathrm{C}$ ) in dependence of the specimen thickness 
CMSX-4 alloy. No breakaway oxidation was detected, even for the thinnest sample, in agreement with the $\gamma$-depleted layer thickness (Fig. 8), which remains much thinner than the half thickness of the sample. Local internal corrosion as depicted in Fig. 7 was evaluated and shown to correspond to a much smaller mass gain (approx. $1 \%$ ) as compared to that of external scale formation. A relatively small volume fraction of TiN nitrides was also observed (Fig. 6), but the corresponding nitrogen mass gain is negligible compared to the oxygen uptake. As a consequence of all these microstructural observations, it was assumed that the isothermal oxidation kinetics during the high temperature dwells of the cyclic oxidation experiments are controlled by the kinetics of alumina growth on this alloy. The parabolic constant determined during isothermal oxidation of CMSX-4 alloy [4] $\left(k_{p}=1.25\right.$. $10^{-6} \mathrm{mg}^{2} \mathrm{~cm}^{4} \mathrm{~s}^{-1}$ ) was then first tested in the present work. It should be mentioned, that the cyclic oxidation leads to linear kinetics due to the formation of mixed scales during the dwell times, however, alumina formation remains rate-controlling.

In order to simulate the cyclic-oxidation kinetics as a function of sample thickness, it is then necessary to vary the extent of spallation that occurs during the anisotherm cooling periods. As shown in Fig. 4, the oxide scale partially spalls, and the extent of spalling depends on the sample thickness. The most simple cyclicoxidation-kinetics model for partial spalling at the oxide/metal interface was proposed by Smialek [11]. Later, Lowell et al. [12] and Smialek and Auping [13] refined this model, which was then termed, COSP (cyclic-oxidation spalling program), and improved its user friendliness. A probabilistic concept of an oxidespalling model was recently proposed by Poquillon and Monceau [1], which allows an easy fitting of the net-mass-change curves. This model simply consists in assuming that a given part of the oxide scale spalls at each cycle. Also, as already assumed, the isothermal oxidation kinetics are parabolic ( $k_{p}$ is constant). Using this so-called " $p-k_{p}$ " model, it is shown here that the net-mass-change data of Fig. 2 could be fitted using the proportion of the scale that spalls after each cycle " $p$ " as a fitting parameter, and using the isothermal value for $k_{p}$. The results of the fit is given in Fig. 5 and the corresponding values are summarized in Table 2. The value of the " $p$ " parameter is clearly increasing with the sample thickness, from $3 \%$ for the $100 \mu \mathrm{m}$ thick sample to $58 \%$ for the $500 \mu \mathrm{m}$ thick sample. This result of simulation is then in general agreement with the experimental observation of spalling after 300 cycles. Nevertheless, the values for the parameter " $p$ " are systematically higher

Table 2 Simulated values referring to the approximation in Fig. 9

\begin{tabular}{lllllll}
\hline $\begin{array}{l}\text { Sample } \\
\text { thickness }\end{array}$ & $t=100$ & $T=200$ & $t=300$ & $t=400$ & $t=500$ & $\mu \mathrm{m}$ \\
\hline $\begin{array}{l}\text { Parabolic } \\
\text { constant }\end{array}$ & $\begin{array}{c}k_{p}= \\
1.25 \cdot 10^{-6}\end{array}$ & $\begin{array}{c}k_{p}= \\
1.25 \cdot 10^{-6}\end{array}$ & $\begin{array}{c}k_{p}= \\
1.25 \cdot 10^{-6}\end{array}$ & $\begin{array}{c}k_{p}= \\
1.25 \cdot 10^{-6}\end{array}$ & $\begin{array}{c}k_{p}= \\
1.25 \cdot 10^{-6}\end{array}$ & $\mathrm{mg}^{2} /\left(\mathrm{cm}^{4} / \mathrm{s}\right)$ \\
$\begin{array}{l}\text { Scale } \\
\text { spalling } \\
\begin{array}{l}\text { at each } \\
\text { cycle } \\
\text { (fitted) }\end{array}\end{array}$ & $p=3 \%$ & $p=12 \%$ & $p=24 \%$ & $p=42 \%$ & $p=58 \%$ & \\
\hline
\end{tabular}




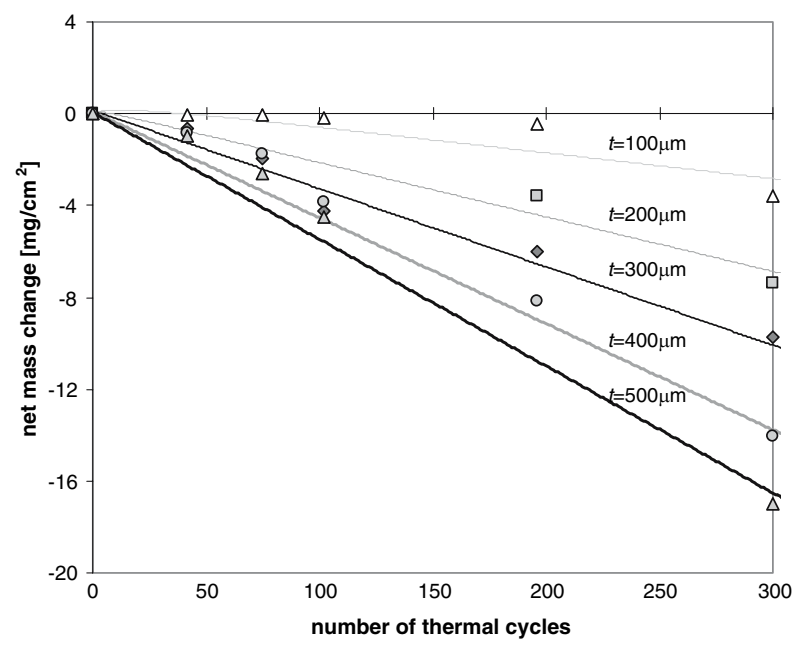

Fig. 9 Simulation (solid lines) of the measured net mass gain data by the use of different spallation probabilities $p$ (see table) in the " $p-k_{P}$-model"

than the percentage of descaled surface area determined by image analysis. This difference may be due to the fact that a proportion of the scale may spall at the alumina/transient oxide interface, with the consequence that the extend of spalling determined by image analysis is lower than the overall extend of spalling measured by mass variation. These differences of values may also be due to the assumption that the parabolic constant for a long-term isothermal annealing applies here for short $1 \mathrm{~h}$ periods. Indeed, if a higher $k_{p}$ value is assumed, a lower " $p$ " value will be found which may be closer to experimental observation. Despites these difficulties, the kinetics modeling reproduce the general behavior of the system. The $\left(p, k_{p}\right)$ values allow to calculate the amount of alloying element consumption [1]. Once an end-of-life criterion has been determined (such as a critical Al concentration in the sample), it would be possible to draw extrapolations of these experiments in order to calculate the time of life of the components as a function of their thickness.

\section{Discussion}

The existence of compressive stresses in alumina scales and the fact that dimensional changes occur in thin metal structures implies that there is, in general, a competition during oxidation between the generation of stresses within the oxide and one or more stress-relaxation mechanisms [14]. Contrary to the experimental results on $\mathrm{Fe}-\mathrm{Cr}-\mathrm{Al}-\mathrm{Y}$ alloys by Tolpygo and Clarke [15], it is unlikely that growth-stresses notably cause relaxation processes in CMSX-4 due to its high strength at elevated temperatures. The comparison of isothermal and thermalcycling exposure tests on wedge-shaped CMSX-4-specimens revealed that isothermal exposure did not deform the tip of the specimen as it was the case for the thermal-cyclical exposed one [4]. This result indicates that stresses resulting from 
temperature changes do significantly contribute to mechanical damage of the substrate as long as the oxide scale remains adherent. It is worth mentioning that oxide-scale cracking occurred not directly in the vicinity of the tip of the wedgeshaped specimens, but somewhat beyond it. This fact was the motivation to put the emphasis on the effect of the specimen thickness in the present study.

The probabilistic spallation model " $p-k_{p}$ " [1] was applied to fit experimental mass changes. The simulation tends to show that the effect of the reduction of the sample thickness is mainly to reduce the amount of spalling without changing the nature of the oxide scale formed. This kinetics modeling also quantifies the consequences of this effect, allowing the calculation of the amount of alloying element consumed by cyclic oxidation. An appropriate continuation of this study should be done by including the effect of the cooling rate in order to assess whether it has a great impact on the stress relief during thermal cycling oxidation or not. However, this would require a quantitative evaluation of the mechanical stresses arising in the scale substrate system, e.g., by applying the finite-element method.

\section{Conclusions}

The presented investigations on specimens exposed under thermal-cycling conditions revealed that the specimen thickness has a great impact on the performance of the alloy. This results in a higher scale-spallation rate and in a higher net mass change, respectively. In the present study, the probabilistic spallation model " $p-k_{p}$ " [1] was applied succesfully to fit experimentally observed spallation. It was shown that the sample-thickness effect can be attributed to differences in the spallation mechanisms rather than differences in the isothermal oxidation kinetics.

Acknowledgement The financial support by the Deutsche Forschungsgemeinschaft (DFG) under grant no. KR1999/2 is gratefully acknowledged. The authors thank Alstom Power, Baden, Switzerland for providing the material used in this study.

\section{References}

1. D. Poquillon and D. Monceau, Oxidation of Metals 59, 409 (2003).

2. J. L. Smialek and G. H. Meier, in Superalloys II, High-Temperature Oxidation. C. T. Sims, N. S. Stoloff, and W. C. Hagel, eds. (John Wiley \& Sons, New York, 1987), Chapter 11, p. 293.

3. R. Orosz, U. Krupp, and H.-J. Christ, Zeitschrift für Metallkunde 96, 775 (2005).

4. R. Orosz, U. Krupp, and H.-J. Christ, Materials and Corrosion 57, 154 (2006).

5. H. E. Evans and A. T. Donaldson, Oxidation of Metals 50, 457 (1998).

6. G. Strehl, D. Naumenko, H. Al-Badary, L. M. Rodriguez Lobo, G. Borchardt, G. Tatlock, and W. J. Quadakkers, Materials at High Temperatures 17, 87 (2000).

7. S. Chang, U. Krupp, and H.-J. Christ, in Proceedings of Cyclic Oxidation of High Temperature Materials (EFC publications, 1999), p. 63.

8. U. Krupp, S. Y. Chang, and H.-J. Christ, Materials Science Forum 369-372, 287 (2001).

9. I. Gurrappa, S. Weinbruch, D. Naumenko, and W. J. Quadakkers, Materials and Corrosion 51, 224 (2000).

10. B. A. Pint, P. F. Tortorelli, and I. G. Wright, Oxidation of Metals 58, 73 (2002).

11. J. L. Smialek, Metallurgical and Materials Transactions A 9A, 309 (1978). 
12. C. E. Lowell, C. A. Barrett, R. W. Palmer, J. V. Auping, and H. B. Probst, Oxidation of Metals 36, 81 (1991).

13. J. L. Smialek and J. V. Auping, Oxidation of Metals 57, 559 (2002).

14. P. Y. Hou, A. P. Paulikas, and B. W. Veal, Materials Science Forum 461-464, 671 (2004).

15. V. K. Tolpygo and D. R. Clarke, Oxidation of Metals 49, 187 (1998). 